\title{
Habitual acceptance of misinformation: Examination of individual differences and source attributions
}

\author{
DAVID R. CANN and ALBERT N. KATZ \\ University of Western Ontario, London, Ontario, Canada
}

\begin{abstract}
This study identifies individuals who are habitually susceptible to accepting postevent misinformation across testing on three separate events. The results indicate that those individuals identified as habitually susceptible exhibited higher dissociation scores and less of an association between memory accuracy and confidence than did the individuals identified as nonhabitually susceptible. When they were asked to identify the source of the remembered information, similar patterns of source attributions were found for all individuals when they were responding correctly and incorrectly to nonmisinformation and when they were correctly rejecting items of misinformation. Importantly, from a source-monitoring perspective, individuals identified as habitually susceptible demonstrated a different pattern of source attributions than did those classified as nonhabitually susceptible when they were accepting misinformation. Habitually susceptible individuals were as likely to attribute the source of their memory incorrectly to something seen in the experienced event as to attribute it correctly to something read after the fact.
\end{abstract}

In most eyewitness memory studies in which the misinformation effect has been investigated, the standard paradigm developed by Loftus and colleagues (e.g., Loftus, 1975; Loftus, Miller, \& Burns, 1978; Loftus \& Palmer, 1974) has been employed. This three-stage paradigm consists of an event-witnessing stage, followed by suggestive misleading postevent information and then a memory test designed to determine whether the participants have accepted the suggested misinformation as part of their memory for the original witnessed event. In general, studies in which this paradigm has been employed have consistently shown that a proportion of individuals exposed to misinformation are more likely to respond in a manner consistent with the misinformation, in comparison with individuals not exposed to misinformation.

Much of the past research on the misinformation effect was directed at discerning various factors that can increase or decrease an individual's susceptibility to misinformation. For example, the wording of misinformation (e.g., Loftus \& Palmer, 1974), a prior warning of the presence of misinformation (e.g., Greene, Flynn, \& Loftus, 1982), and suggesting misinformation that is blatantly false (e.g., Tousignant, Hall, \& Loftus, 1986) have been shown to influence misinformation acceptance. The focus of this article is somewhat different: identifying individual differences

This research was supported by Natural Sciences and Engineering Research Council of Canada Operating Grant NSERC 06P007040 to A.N.K. The authors thank two anonymous reviewers for their helpful comments and suggestions on earlier versions of this article. Marcia K. Johnson is thanked for her thoughtful comments and most helpful suggested revisions to various sections of the article-in particular, the introduction. Address correspondence to D. R. Cann or A. N. Katz, Department of Psychology, University of Western Ontario, London, ON, N6A 5C2 Canada. (e-mail: dcann@uwo.ca orkatz@uwo.ca). associated with people who have a propensity to repeatedly accept misinformation as having occurred in previously witnessed events. Of special interest is whether individuals identified as habitually susceptible to misinformation acceptance differ from nonsusceptible individuals on their monitoring of the source of the misinformation.

A generally agreed upon explanation for the results from misinformation effect studies is provided by the sourcemonitoring framework proposed by Johnson, Hashtroudi, and Lindsay (1993; see also Johnson \& Raye, 1981; Mitchell \& Johnson, 2000). Within this framework, memories are the result of processes by which mental experiences are attributed to sources. These attributions are sometimes erroneous, because the distributions of the various features of information from different sources overlap and because other factors (e.g., prior knowledge, beliefs, desires, and so on) influence memory attributions. Therefore, factors that increase the overlap between the memories from various sources (e.g., vivid imagery would increase the overlap between perceived and imagined events), that reduce the criteria required for attributions to a particular source (e.g., a desire to believe that a particular source was the origin or a susceptibility to social influence), or that contribute supporting evidence (e.g., activated schemas or stereotypes) would tend to increase source errors. Of course, these factors might vary within an individual on different occasions or across different situations, accounting for withinindividual variability in susceptibility to misinformation.

One can also consider variability that occurs between individuals. That is, within the source-monitoring framework, there may be individuals who are habitually susceptible to accepting misinformation - for example, individuals with poorer memories of the features of events (leading to more overlap in memories from different 
sources) who experience imagery more vividly, who habitually adopt inappropriate or lax criteria when evaluating the origin of mental experiences, or who are habitually susceptible to social influence.

Some support for an individual difference perspective comes from a study reported by Tomes and Katz (1997). They tested the same individuals on three separate independent events, using in each case a standard misinformation paradigm. Individuals who accepted some misinformation on the memory test in each of the three events were identified as habitually susceptible. Habitually susceptible individuals differed from those less susceptible in terms of poorer overall memory for the event, higher self-ratings of imagery vividness, and higher empathy scores. The aim of the present research was to examine additional psychometric individual difference variables that might potentially discriminate between individuals who are habitually susceptible and those who are not habitually susceptible and to relate habitual susceptibility to differences in source attribution.

The psychometric variables selected for the present study were chosen in accord with theoretical and empirical rationales and for the possible insights they might provide for the understanding of habitual susceptibility. The source-monitoring literature has specified a variety of factors (e.g., use of lax decision criteria) that influence source attributions (for a review, see Mitchell \& Johnson, 2000), and these were considered when some of the individual difference variables were selected. Moreover, research in the false memory literature has empirically demonstrated relations between false memory creation and various individual difference variables, and findings from this literature also guided the selection of variables (e.g., Hyman \& Billings, 1998; Paddock, Terranova, Kwok, \& Halpern, 2000; Winograd, Peluso, \& Glover, 1998). In all, 11 variables were measured in the present study, and these included confidence-accuracy calibration measures for both misinformation items and nonmisinformation items, total accuracy on nonmisinformation items, dissociation, absorption, vividness of imagery, dysphoria, state self-esteem, external locus of control, fear of negative evaluation, and boredom proneness. The rationale for including each individual difference measure in the present study will be described when these measures are presented in the Method section.

To anticipate the major findings of the present study, both the measure of dissociation and the confidenceaccuracy calibration measure for misinformation items were significantly related to habitual susceptibility. Moreover, people who habitually accepted misinformation differed in their attributions for the source of the misinformation from those who did accept misinformation, but not habitually, and from control participants who were never presented with misinformation.

\section{METHOD}

\section{Participants}

All the participants were enrolled in an introductory psychology course at the University of Western Ontario. The participants were re- cruited from the university participant pool, and all received course credit. In all, 194 individuals (104 males and 90 females) participated, ranging in age from 18 to 27 years $(M=19.74)$. Forty-four of these individuals ( 24 males and 20 females) were randomly assigned to the control condition, with the remaining 150 participants $(80$ males and 70 females) assigned to the experimental condition. ${ }^{1}$ In addition, half of the participants in each condition completed an explicit source-monitoring task. As had been done by Tomes and Katz (1997), a larger number of the participants were assigned to the experimental condition, because one focus of the study was to examine the predictability of individual difference measures on those who are habitually susceptible to acceptance of misinformation. Because only a relatively small portion of the population is expected to be habitually susceptible, a larger experimental group is necessary. The participants were tested in groups of 4-12, with an average group size of 6 .

\section{Materials}

Video clips and misinformation questionnaires. Three different video clips were used, each depicting a crime scene lasting between $1 \mathrm{~min} 30 \mathrm{sec}$ and $1 \mathrm{~min} 50 \mathrm{sec}$. The participants viewed all three of these video clips. These clips and their accompanying questionnaires were taken from the materials used by Tomes and Katz (1997; see Appendix A for the misinformation items and Tomes \& Katz, 1997, for a complete description of the video clips). Each video clip was followed by two sets of questionnaires, each consisting of 15 yes/no questions. The participants were also asked to rate the confidence level of their answer for each of the questions on a scale of 1 (not confident) to 5 (very confident). The first (manipulation) questionnaire for each video clip presented 4 questions that contained misinformation, along with 11 questions not containing misinformation (note that one question from the $Z$ video presented two items of misinformation, resulting in 12 nonmisinformation questions on this particular questionnaire). The control group completed an identical questionnaire, with the exception that the implied misinformation was removed from the items. The second (assessment) questionnaire for each video clip assessed whether or not the 4 misinformation items had been accepted as part of the original event and was completed by all the participants. Overall memory for the event was assessed according to the accuracy of the participants' responses to all 67 items not containing misinformation from both the manipulation and the assessment questionnaires.

Source-monitoring task. After completion of the second questionnaire associated with a video clip, half the participants (as was noted above) were presented with a sheet numbered to correspond to the 15 questions they had just answered. Next to each number were a yes/no response and five alternative source response options (i.e., saw, read, both, don't know, and neither). Higham (1998) suggested this five-source option in order to rule out the possibility of source guessing arising from familiarity misjudgments. The meaning of the first three of these options is self-evident. Inclusion of the don't know response allowed the participants the opportunity to be noncommittal with their source attribution, thus ruling out source attributions based on guessing. This response is equivalent to saying "I know it occurred somewhere in the context of the experiment, but I don't know where." The neither response option allowed the participants the opportunity to indicate that they had answered the yes/no question but had no real reason for answering it the way in which they did. The instructions for the source task are presented in the Procedure section.

\section{Individual Difference Measures}

Confidence-accuracy. Tomes and Katz (1997) and others (e.g., Loftus, Levidow, \& Duensing, 1992) hypothesized that if individuals have poor overall memory for the original event, they are likely to be more susceptible to misinformation, and both studies provided support for this hypothesis. Moreover, Tomes and Katz (2000) reported a strong positive confidence-accuracy calibration for items not involving misinformation but virtually no confidence-accuracy 
calibration for misinformation items. The Goodman-Kruskal gamma correlation (see Nelson, 1984, 1987) was used to obtain a measure of the calibration of confidence and accuracy for each participant and, as such, is treated as an individual difference variable that provides a measure of feeling-of-knowing (Nelson, 1984). As had been done by Tomes and Katz (2000), two gamma correlations were calculated for each participant: one calibrating a participant's confidenceaccuracy relation for misinformation items (MI gamma) and the other calibrating the confidence-accuracy relation for nonmisinformation items (NMI gamma). To calculate the gamma correlation for a participant, the number of concordant pairs (confident with a correct item response or not confident with an incorrect item response) and the number of discordant pairs (confident with an incorrect item response or not confident with a correct item response) were examined. For present purposes, choosing the value 1 or 2 on the 5-point confidence scale indicates a nonconfident response, and a confident response was indicated by choosing one of the remaining values (i.e., 3,4 , or 5). The basic formula for the gamma is (concordant pairs - discordant pairs)/(concordant pairs + discordant pairs). The gamma correlation can range from -1.00 to 1.00 , and like parametric correlations, values closer to the absolute value of 1 represent stronger relations between the variables of interest, and values close to 0 represent weak relations.

Dissociation. Dissociation is defined as the "lack of the normal integration of thoughts, feelings, and experiences into the stream of consciousness and memory" (Bernstein \& Putnam, 1986, p. 727). Various studies (e.g., Hyman \& Billings, 1998; Winograd et al., 1998) have noted significant relations between this variable and the creation of false memories (but see Drivdahl \& Zaragoza, 2001, and Platt, Lacey, Iobst, \&, Finkelman, 1998, in which no relation was found). Winograd et al. suggested that those reporting dissociative experiences might be prone to false memory creation because they fail to properly monitor the source of their memories. To our knowledge, no studies have been done to examine the potential relation between dissociation and habitual susceptibility. Dissociation was measured in the present study with Goldberg's (1999) Curious Experiences Survey (CES; see also Cann \& Harris, 2003). The CES consists of 31 statements that are responded to on a 5-point Likerttype scale $(1=$ never, 5 = always $)$ with higher scores being indicative of self-reported dissociative experiences.

Absorption. Tellegen and Atkinson (1974) defined absorption "as a disposition for having episodes of 'total' attention that fully engages one's representational (i.e., perceptual, enactive, imaginative, and ideational) resources" (p. 268). Destun and Kuiper (1996) have suggested that absorption may play a role in the creation of false autobiographical memories, and Platt et al. (1998) have reported support for this contention. Platt et al. has suggested further that absorption might be related to susceptibility to misinformation acceptance. This was examined in the present study, and absorption was measured with the 50-item Individual Difference QuestionnaireAbsorption (IDQ-A; Destun, 1994). Participants respond to each item on a 5-point Likert-type scale ranging from 1 (never) to 5 (almost always). The IDQ-A is a compilation of various measures of absorption and related constructs and was constructed to be a more comprehensive measure of absorption (Destun, 1994).

Dysphoria. MacFarland and Morris (1998) reported that dysphoric individuals are more suggestible in general than nondysphoric individuals are, and this was examined in the present study in the context of habitual susceptibility. Dysphoria was measured with the 21-item Beck Depression Inventory (BDI; Beck, Rush, Shaw, \& Emery, 1979). High scores on the BDI reflect dysphoria, or negative affect, which Kendall, Hollon, Beck, Hammen, and Ingram (1987) have stated is not specific to depression. As had been done by MacFarland and Morris and suggested by Kendall et al., participants scoring 9 or above on the BDI were classified as dysphoric, and all others were classified as nondysphoric.

Emotional self-focus. Mitchell and Johnson (2000) have suggested that focusing on one's own emotions might be disruptive to memory-encoding processes and potentially lead to source confusions when one is later tested for the source of the memory. Two individual difference variables potentially related to emotional selffocus were examined in the present study. The first was fear of negative evaluation, a component of social-evaluative anxiety, and this was measured with the Fear of Negative Evaluation Scale (FNE; Watson \& Friend, 1969). Gudjonsson (1988) has reported a modest positive relation between fear of negative evaluation and suggestibility, suggesting a possible relation between this variable and habitual susceptibility. Participants respond true or false for each of the 30 items that make up this measure. Higher scores on this measure are indicative of greater social-evaluative anxiety or fear of negative evaluation.

The second individual difference variable that may be related to emotional self-focus is that of state self-esteem, and the State SelfEsteem Scale (SSES; Heatherton \& Polivy, 1991) was used to measure the participant's level of self-esteem during the testing session. A measure of state self-esteem was chosen, rather than a general trait selfesteem measure, because the situational context of answering suggestive questions may lead individuals to doubt their abilities. The SSES consists of 20 items that are rated on a 5-point Likert-type scale. High scores on this measure are indicative of low state self-esteem.

Boredom proneness. The source-monitoring framework also predicts that the criteria adopted when determining the source of a memory can influence the attribution made (Mitchell \& Johnson, 2000). Leary, Rogers, Canfield, and Coe (1986) have argued that an individual's experienced level of boredom is a function of the cognitive effort required to sustain focused attention. As such, it seems reasonable that boredom-prone individuals would be less likely to thoroughly evaluate the source of their memory before making an attribution, thus making them habitually susceptible to misinformation acceptance. The 28 -item Boredom Proneness Scale (BPS; Farmer \& Sundberg, 1986) was used in the present study to measure self-reported levels of boredom for the participants. Participants respond to each item on this scale by indicating whether the statement is true or false for them. Higher scores on this measure are indicative of higher levels of boredom.

Locus of control. Paddock et al. (1998) and Paddock et al. (2000) have reported that individuals with an external locus of control are more vulnerable to suggestion and, consequently, more likely to commit source-monitoring errors. The college form of the Adult Nowicki-Strickland Internal-External Control Scale (ANSIE; Nowicki \& Duke, 1983) was used to measure locus of control. Participants respond yes or no, as applicable, to this 40 -item measure. High scores on this measure indicate an external locus of control.

Vividness of visual imagery. Many studies (e.g., Tomes \& Katz, 1997; Winograd et al., 1998) have provided evidence of a relation between imagery vividness and suggestibility. Consistent with predictions from the source-monitoring framework (e.g., Johnson et al., 1993), Dobson and Markham (1993) demonstrated a direct relation between self-reported imagery abilities and source errors, in which high imagers were more likely than low imagers to misattribute the source of their memory. Vividness of visual imagery was assessed with the Vividness of Visual Imagery Questionnaire (VVIQ-2; Marks, 1995). Participants are asked to visualize each of the 32 items and then rate the vividness of their image on a 5-point scale. High scores on the VVIQ-2 indicate vivid visual imagery.

\section{Procedure}

The participants in this study were informed that they were participating in a study of memory for movies and that their memory for the event viewed would be tested. They were not informed that some of the postevent questions contained misinformation. The participants were first instructed to pay close attention to the video presentation. After viewing a video clip, the participants were asked to complete the first set of 15 (yes/no) questions pertaining to the video they had just viewed. 
After completing the first question set related to the video clip that was viewed, the participants then completed some of the individual difference measures. These measures were organized into three assessment packages. The completion of each assessment package took approximately $15 \mathrm{~min}$ and served as a delay period before the participants were assessed for misinformation acceptance. The first package contained the boredom-proneness and the fear-of-negative-evaluation measures. The items from both of these measures were randomly combined into one 58 -item questionnaire. The final portion of the first assessment package consisted of 10 items randomly drawn from the locus-of-control measure. The second assessment package contained the measure of absorption and 20 items randomly chosen from the locus-of-control measure. The third assessment package consisted of the dissociation measure, the dysphoria measure, and the final 10 items from the locus-of-control measure.

After completing an individual difference assessment package, the participants were presented with a second set of questions (15 yes/no items) that assessed whether or not they had accepted the misinformation presented earlier and had reported an altered memory for the event witnessed. After completion of this set of misinformation acceptance questions, half of the participants in each condition were instructed that some people tend to rush through the questions without giving much thought to the answers they give. ${ }^{2}$ As such, these participants were further instructed, "We would like you to reread each question and think about why you responded yes or no to each question. On the sheet of paper provided, re-answer each question by circling yes or no again, you may change any of your original answers if you wish. Then, by circling one of the response options (saw, read, both, don't know, or neither), we would like you to indicate the source from which you base your yes/no response. That is, if your yes/no response is based on your memory of the video, circle saw, if it is based on something you read in the questions answered about the video, circle read, if it is based on your memory of the video and the questions, circle both, if you are unsure if your response is based on the video or the questions, but know that it is based on something that occurred during the experiment, circle don't know, and finally, if you have no idea why you responded the way in which you did, circle neither." As has been indicated, these participants had their original yes/no response available to them during the source identification task and were instructed that they could change their original response. ${ }^{3}$

In summary, the pattern for one trial consisted of watching a video clip, presentation of misinformation, completion of one of the individual difference packages, and assessment of misinformation acceptance (and source identification, if applicable). This pattern was repeated for the second and third video clips. The individual difference packages were always presented in a fixed order-first package, second package, and third package - as was discussed above. The video clips were presented randomly, so that each of the video clips was presented first, second, and third equally often. After all of the measures had been completed in the third trial, the participants were presented with the state self-esteem measure and the measure of imagery vividness. The participants were presented with these measures last in order to avoid any potential bias effects, because the explicit nature of the imagery measure may invoke its use and because interest was in the aftereffects of suggestive questioning on state selfesteem. After completion of these measures, the participants were told the nature of the study and were provided with a written feedback form, and any questions they may have had were answered. The total time to complete the study was approximately $75 \mathrm{~min}$.

\section{RESULTS}

\section{Overall Memory Performance}

To examine overall accuracy on the 67 items that did not contain or assess misinformation, the responses of the participants not exposed to misinformation (the con- trol condition) were compared with the responses of the two groups of participants exposed to misinformation (the source and nonsource conditions). The right-hand panel of Table 1 presents the means and standard deviations for the number of correct responses on the nonmisinformation items for the participants in these three groups. Overall, performance by the three groups of participants was comparable on these 67 items $[F(2,193)=$ $0.07, M S_{\mathrm{e}}=12.01, \mathrm{n} . \mathrm{s}$.]. The number of correct responses by all the participants on these nonmisinformation items ranged from 43 (64\% correct) to 64 (96\% correct), with an average of $87 \%$, which is consistent with the results reported in Tomes and Katz (1997). This finding indicates that, regardless of condition, the participants were fairly accurate when responding to items assessing their veridical memory of witnessed events.

The responses when the 12 items of misinformation (from the first yes/no assessment questionnaire) were accepted were summed to determine whether the items of misinformation had an effect on the responses given by the participants in the two experimental conditions, when compared with the responses given by the participants in the control condition (see the left-hand panel of Table 1 for the means and standard deviations when misinformation items were accepted). This analysis resulted in significant between-condition differences $[F(2,193)=$ 13.08, $\left.M S_{\mathrm{e}}=4.54, p<.001\right] .{ }^{4}$ Post hoc tests using Tukey's HSD indicated that the two experimental conditions did not significantly differ from each other but that both of these conditions did significantly differ from the control condition $(p<.001)$. The participants in the two experimental conditions were more likely to respond in a manner indicating their acceptance of the misinformation items than were those participants in the control condition. This finding replicates the general misinformation effect reported in the literature, in which participants exposed to misinformation are more likely to report it as having occurred in the event witnessed.

\section{Identifying and Discriminating Habitual Susceptibility to Misinformation}

Habitual susceptibility was defined, as in Tomes and Katz (1997), as acceptance of at least one item of misinformation for each of the three video clips. As in previous studies (e.g., Loftus et al., 1992; Tomes \& Katz, 1997), not all misinformation items were included in this susceptibility analysis. A set of effective misinformation

Table 1

Means and Standard Deviations for Correct Responses on Nonmisinformation Items (67) and Acceptance of Misinformation Items (12) for the Three Conditions

\begin{tabular}{|c|c|c|c|c|}
\hline \multirow[b]{3}{*}{ Condition } & \multicolumn{4}{|c|}{ Item Type } \\
\hline & \multicolumn{2}{|c|}{ Misinformation } & \multicolumn{2}{|c|}{ Nonmisinformatior } \\
\hline & $M$ & $S D$ & $M$ & $S D$ \\
\hline Nonsource $(n=75)$ & 4.91 & 2.16 & 57.99 & 3.52 \\
\hline Source $(n=75)$ & 4.83 & 2.30 & 58.07 & 3.74 \\
\hline Control $(n=44)$ & 3.00 & 1.75 & 58.23 & 2.81 \\
\hline
\end{tabular}


items was defined as individual items of misinformation for which the acceptance responses in each of the two experimental conditions differed significantly from those in the control condition and for which the acceptance responses in the two experimental conditions did not differ significantly from each other. ${ }^{5}$ Four items of misinformation were identified from these analyses. These included one item from the Big Sweat video [BA2, $F(2,193)=$ 4.78, $\left.M S_{\mathrm{e}}=0.21, p<.01\right]$, one item from the $Z$ video $\left[\mathrm{ZA} 4, F(2,193)=13.08, M S_{\mathrm{e}}=0.23, p<.001\right]$, and two items from the Talons of the Eagle video [TA2, $F(2,193)=$ $4.18, M S_{\mathrm{e}}=0.24, p<.05$; TA4, $F(2,193)=8.78, M S_{\mathrm{e}}=$ $0.23, p<.001]$. The means and standard deviations, in which higher scores are more indicative of responding $y e s$, for these four effective items of misinformation for the three conditions are presented in Table 2, and all of the misinformation items are presented in Appendix A.

Consistent with Tomes and Katz (1997), individuals were then classified according to the number of video events for which they accepted at least one item of misinformation per event. As in the earlier study, most people $(95.3 \%)$ accepted misinformation on at least one of the three events viewed, but fairly few $(26.2 \%)$ accepted some misinformation on all three events. It is the latter that we designated as habitually susceptible to accepting misinformation.

The following results will focus on identifying possible individual differences that discriminate individuals identified as habitually susceptible to misinformation from those less susceptible to the effects of misinformation. Only the data from the participants in the two experimental conditions were utilized in these analyses. In order to determine what individual difference variables discriminate between habitual and nonhabitual participants, it was decided to collapse across the two experimental conditions for the reported analyses. ${ }^{6}$ The group labeled habitually susceptible (accepting misinformation in each of the three events) comprised $26.2 \%(n=$ $39 ; 1$ participant identified as habitually susceptible was excluded from the present analyses because of incomplete individual difference data) of the experimental condition participants, whereas the nonhabitual group (accepting misinformation in two or fewer events) comprised $73.8 \%$ $(n=110)$ of the experimental condition participants. Table 3 presents the means and standard deviations for the two groups on the individual difference measures,

Table 2

Means and Standard Deviations for the Common Set of Accepted Misinformation Items (4) for the Three Conditions (Where $0=$ not accepted and $1=$ accepted $)$

\begin{tabular}{|c|c|c|c|c|c|c|c|c|}
\hline \multirow[b]{3}{*}{ Condition } & \multicolumn{8}{|c|}{ Misinformation Item } \\
\hline & \multicolumn{2}{|c|}{ BA2 } & \multicolumn{2}{|c|}{ ZA4 } & \multicolumn{2}{|c|}{ TA2 } & \multicolumn{2}{|c|}{ TA4 } \\
\hline & $M$ & $S D$ & $M$ & $S D$ & $M$ & $S D$ & $M$ & $S D$ \\
\hline Nonsource $(n=75)$ & .37 & .49 & .55 & .50 & .64 & .48 & .65 & .48 \\
\hline Source $(n=75)$ & .39 & .49 & .59 & .50 & .61 & .49 & .55 & .50 \\
\hline Control $(n=44)$ & .14 & .35 & .23 & .42 & .39 & .49 & .27 & .45 \\
\hline
\end{tabular}

Note-The actual items are presented in Appendix A. and the rightmost column in this table presents pointbiserial correlations between habitual susceptibility and the individual difference measures. For these correlations, habitual susceptibility to misinformation acceptance was dummy-coded as one (1) and nonhabitual susceptibility was dummy-coded as zero (0). This was also the case for dysphoria (nondysphoric $=0$ and dysphoric $=1$ ). The intercorrelations among the various individual difference variables are presented in Appendix B. As Table 3 illustrates, habitual susceptibility was related to four of the individual difference variables. Habitually susceptible individuals tended to report more dissociative experiences, had higher scores on the measure of dysphoria, reported lower levels of state self-esteem, and demonstrated virtually no calibration (i.e., mean MI gamma was near zero; see Table 3) between their confidence and accuracy on the items of misinformation.

To determine whether the set of individual difference measures could predict habitual susceptibility to misinformation acceptance, a logistic regression analysis was conducted using the forced entry procedure. ${ }^{7}$ A significant regression equation was obtained $\left[\chi^{2}(11, n=150)=\right.$ $35.67, p<.001]$, with a Nagelkerke $R^{2}$ value of .31. Two of the individual difference measures were significant predictors of habitual susceptibility when the effects of the other variables were removed statistically: the misinformation gamma measure $(\beta=-9.74, p<.001)$ and the measure of dissociation $(\beta=0.05, p<.01)$. The partial correlations for these two measures with habitual susceptibility were -.33 and .23 , respectively.

\section{Source Monitoring}

Recall that a major aim of the study was to relate habitual acceptance of misinformation to source attribution. In this section, we will examine the source attributions made by the participants who completed the sourcemonitoring task. Unlike previous research (e.g., Lindsay \& Johnson, 1989), the intent was not to determine whether source monitoring would reduce misinformation acceptance but simply to examine the source that individuals would attribute to their yes/no responses. Conditional probabilities were calculated for individuals on the basis of their category of response (i.e., yes or no) and their corresponding source attributions to that category for both the misinformation and the nonmisinformation items. As such, four 3 (group: control, habitual, or nonhabitual) $\times 5$ (source attribution) split plot analyses of variance (ANOVAs) are presented, using conditional probability as the dependent variable. No main effect of group will be reported with these analyses, because all the probabilities must sum to one. Thus, our interest is in the main effect of type of source and the group $\times$ type of source interaction. The second yes/no response for all of these items was used when the conditional probabilities were calculated. The aim of these analyses was to determine whether the pattern of source attributions differed for the control group and the two groups identified earlier as habitually and nonhabitually susceptible to misinformation acceptance. The degrees of freedom for the 
Table 3

Means, Standard Deviations, and Possible Score Ranges for the Habitual and Nonhabitual Individuals on the Individual Difference Measures and Point-Biserial Correlations Between Habitual Status (HAB) and the Individual Difference Measures

\begin{tabular}{|c|c|c|c|c|c|c|c|}
\hline \multirow[b]{2}{*}{ Measure } & \multirow{2}{*}{$\begin{array}{c}\text { Possible } \\
\text { Score Range }\end{array}$} & \multicolumn{2}{|c|}{ Habitual } & \multicolumn{2}{|c|}{ Nonhabitual } & \multirow{2}{*}{$\begin{array}{c}t \text { Value } \\
(d f=148)\end{array}$} & \multirow{2}{*}{$\begin{array}{c}\mathrm{HAB} \\
r_{p b}\end{array}$} \\
\hline & & $M$ & $S D$ & $M$ & $S D$ & & \\
\hline MI gamma & $-1.0-1.0$ & .03 & .11 & .10 & .08 & $4.2^{* *}$ & $-.33^{* *}$ \\
\hline NMI gamma & $-1.0-1.0$ & .67 & .18 & .70 & .19 & .90 & -.07 \\
\hline Acc & $0-67$ & 57.9 & 3.5 & 58.1 & 3.7 & 0.26 & -.02 \\
\hline CES & $31-155$ & 67.6 & 15.0 & 60.0 & 13.2 & $-2.9^{*}$ & $.24^{* *}$ \\
\hline ABS & $50-250$ & 154.3 & 28.5 & 154.0 & 26.4 & -0.06 & .005 \\
\hline VVIQ & $32-160$ & 122.9 & 23.4 & 122.3 & 20.3 & -0.15 & .01 \\
\hline SSES & $20-100$ & 67.9 & 12.5 & 73.9 & 12.3 & $2.6^{*}$ & $-.21^{*}$ \\
\hline Dysph & $0-1$ & .56 & .50 & .33 & .47 & $-2.6^{*}$ & $.21^{*}$ \\
\hline EXT & $0-40$ & 12.4 & 4.7 & 11.4 & 4.7 & -1.1 & .09 \\
\hline FNE & $0-30$ & 13.3 & 7.3 & 11.1 & 7.3 & -1.6 & .13 \\
\hline BPS & $0-28$ & 9.8 & 4.4 & 9.4 & 4.8 & -0.46 & .04 \\
\hline
\end{tabular}

Note-MI gamma, misinformation confidence-accuracy gamma; NMI gamma, nonmisinformation confidence-accuracy gamma; Acc, veridical memory accuracy; CES, dissociation; ABS, absorption; VVIQ, imagery use; SSES, state self-esteem; Dysph, dysphoria; EXT, external locus of control; FNE, fear of negative evaluation; BPS, boredom proneness. $\mathrm{HAB}, 1=$ habitual and $0=$ nonhabitual. ${ }^{*} p<$ $.01{ }^{* *} p<.001$.

analyses reported below are based on the GreenhouseGeisser adjustment. The first two analyses focused on the source attributions when the participants were responding correctly and incorrectly to the items that did not contain misinformation (33 items in all). The last two analyses were performed to examine source attributions when misinformation was incorrectly accepted (i.e., responding yes) and when misinformation was correctly rejected (i.e., responding no; 12 items in all). ${ }^{8}$ As was mentioned earlier, some individuals did not accept any items of misinformation; as a result, these individuals were excluded from the analysis performed to examine source attributions when misinformation was accepted (the group sizes for each analysis are included in the respective tables that follow).

Source attributions for nonmisinformation items. The upper panel of Table 4 presents the means and standard deviations of the conditional probabilities for the five source options for each of the three groups when they were responding correctly to the nonmisinformation items. There was a significant main effect of source attribution $\left[F(3,214)=703.70, M S_{\mathrm{e}}=0.02, p<.001\right]$, indicating that the proportion of attributions to each source differed. That is, regardless of group, all the participants were far more likely to attribute their correct responses for these items to something that they remembered seeing in the video event. The group $\times$ source attribution interaction was not significant $\left[F(5,214)=1.28, M S_{\mathrm{e}}=0.02\right]$.

The lower panel of Table 4 presents the means and standard deviations of the conditional probabilities for the nonmisinformation items when they were answered incorrectly for each of the three groups. Once again, the interaction was not significant $\left[F(5,217)=0.51, M S_{\mathrm{e}}=\right.$ $0.07]$. As above, the proportion of attributions to each source was significantly different $[F(3,217)=127.3$, $\left.M S_{\mathrm{e}}=0.07, p<.001\right]$, with again, the saw option the predominate attribution.
In summary, for items in which there was no postevent misinformation presented, all the groups tended to attribute their memories, whether correct or not, to something seen in the event.

Source attributions for misinformation items. The upper panel of Table 5 presents the means and standard deviations for each of the source response options when items of misinformation were accepted, for each of the three groups, expressed as conditional probabilities. The main effect of source attribution $\left[F(3,231)=40.37, M S_{\mathrm{e}}=\right.$ $0.09, p<.001]$ was significant. Importantly, the group $\times$ source interaction also was significant $[F(5,231)=4.53$, $\left.M S_{\mathrm{e}}=0.09, p<.001\right]$, indicating that the pattern of source attributions differed as a function of group.

To determine how the source attributions for each group differed, post hoc tests were conducted contrasting each possible pair of source attributions within a

Table 4

Conditional Probabilities of Source Attributions for Each Group When Responding Correctly and Incorrectly to the 33 Items of Nonmisinformation

\begin{tabular}{|c|c|c|c|c|c|c|c|c|c|}
\hline \multirow[b]{3}{*}{ Group } & \multicolumn{9}{|c|}{ Response } \\
\hline & \multicolumn{2}{|c|}{ Saw } & \multicolumn{2}{|c|}{ Read } & \multicolumn{2}{|c|}{ Both } & \multicolumn{2}{|c|}{ Neither } & $\begin{array}{l}\text { Don't } \\
\text { Know }\end{array}$ \\
\hline & $M$ & $S D$ & $M$ & $S D$ & $M$ & $S D$ & $M$ & $S D$ & $S D$ \\
\hline
\end{tabular}

Source Attribution When Responding Correctly to Nonmisinformation $\begin{array}{lllllllllll}\text { Control } & .74 & .10 & .03 & .05 & .05 & .08 & .11 & .13 & .07 & .07\end{array}$ $\begin{array}{lllllllllll}\text { Habitual } & .78 & .17 & .02 & .02 & .03 & .06 & .09 & .14 & .08 & .08\end{array}$ $\begin{array}{lllllllllll}\text { Nonhabitual } & .80 & .15 & .02 & .06 & .05 & .06 & .06 & .07 & .07 & .09\end{array}$

Source Attribution When Responding Incorrectly to Nonmisinformation $\begin{array}{lllllllllll}\text { Control } & .63 & .24 & .06 & .19 & .03 & .08 & .15 & .21 & .13 & .15\end{array}$ $\begin{array}{lllllllllll}\text { Habitual } & .71 & .25 & .01 & .03 & .01 & .04 & .16 & .28 & .11 & .15\end{array}$ $\begin{array}{lllllllllll}\text { Nonhabitual } & .65 & .27 & .03 & .09 & .04 & .09 & .12 & .20 & .16 & .20\end{array}$ Note-Sample sizes were the following: control, $n=21$; habitual, $n=20$; nonhabitual, $n=54$. 
group, using Tukey's HSD with alpha set at .05. Significantly more attributions were made to the saw response than to any other attribution response for the control group. No other comparisons were significantly different for this group. The individuals in the nonhabitual group made significantly more saw attributions than any of the other possible attribution responses. The nonhabituals also made significantly more read responses than neither or don't know responses. No other comparisons were significantly different for this group. In contrast, the habitual group was equally likely to give a saw or read attribution when accepting misinformation but made significantly more saw attributions, when compared with the other three possible attributions. Similarly, significantly more read attributions were made, when compared with both, neither, and don't know attributions. No other comparisons were significantly different.

The lower panel of Table 5 presents the means and standard deviations for each of the source response options when items of misinformation were correctly rejected, expressed as conditional probabilities, for each of the three groups. For this analysis, the group $\times$ source interaction $\left[F(5,217)=1.64, M S_{\mathrm{e}}=0.04\right]$ was not significant. The main effect of source attribution was significant $\left[F(3,217)=292.33, M S_{\mathrm{e}}=0.04, p<.001\right]$, indicating that the predominate response across the three groups was to the saw response option.

In summary, analogous to what was reported for nonmisinformation items, for items subjected to postevent misinformation all three groups attributed their memories to something seen in the event presented, when they correctly rejected the misinformation. However, when accepting misinformation, the habitual and the nonhabitual participants differed: Nonhabitual individuals were reliably more likely to attribute a false memory to something seen in the event, whereas habitually susceptible individuals were as likely to attribute the memory to

Table 5

Conditional Probabilities of Source Attributions for Each Group When Accepting and Rejecting the 12 Items of Misinformation

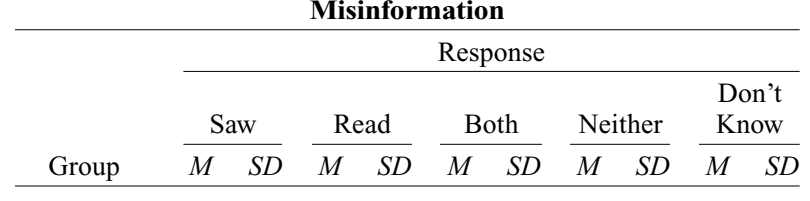

Source Attribution When Accepting Misinformation

$\begin{array}{lllllllllll}\text { Control } & .66 & .35 & .03 & .09 & .03 & .09 & .11 & .22 & .17 & .30\end{array}$ $\begin{array}{lllllllllll}\text { Habitual } & .39 & .27 & .38 & .22 & .10 & .11 & .03 & .08 & .10 & .14\end{array}$ $\begin{array}{lllllllllll}\text { Nonhabitual } & .50 & .32 & .27 & .28 & .14 & .23 & .03 & .10 & .06 & .14\end{array}$

Source Attribution When Rejecting Misinformation

$\begin{array}{lllllllllll}\text { Control } & .69 & .16 & .05 & .11 & .01 & .04 & .11 & .17 & .14 & .13\end{array}$ \begin{tabular}{lllllllllll} 
Habitual & .73 & .23 & .01 & .06 & .04 & .09 & .10 & .18 & .12 & .20 \\
Nonhabital & .78 & .21 & .03 & .06 & .06 & .09 & .05 & .10 & .08 & .13 \\
\hline
\end{tabular} \begin{tabular}{lllllllllll} 
Nonhabitual & .78 & .21 & .03 & .06 & .06 & .09 & .05 & .10 & .08 & .13 \\
\hline
\end{tabular}

Note-Accepting misinformation is indicative of responding yes to an item, and rejecting misinformation is indicative of responding $n o$ to an item. The sample sizes for the upper panel were the following: control, $n=17$; habitual, $n=20$; nonhabitual, $n=53$. For the lower panel, the sample sizes were 21,20 , and 54 , respectively. something read (the correct source) as to something seen (the incorrect source).

\section{DISCUSSION}

The findings are clear. First, as in Tomes and Katz (1997), there were some individuals identified as especially susceptible to accepting postevent misinformation as an event memory. In contrast to the usual observation in misinformation studies in which a single event has been employed, where only a proportion of the sample is susceptible to the misinformation effect, the present study suggests that when individuals are given enough opportunities to report misinformation, they tend to do so. Indeed, in this study, $95.3 \%$ of our participants accepted some misinformation on at least one of the three events viewed, a proportion reasonably similar to that reported by Tomes and Katz (1997), who reported that only $2 \%$ of their participants exposed to misinformation were completely resistant to reporting the misinformation. The importance of this finding is directly related to false memory studies - including, but not limited to, misinformation studies - in which individual differences are examined as contributing factors in illusory memory creation. In general, in these studies, illusory memory creation is not examined as an individual difference variable. As such, individuals that create, or report, illusory memories in these studies may do so only occasionally and may not demonstrate a tendency or predisposition to do so repeatedly. This reasoning may explain why some of the individual differences measured in the present study, and selected on the basis of demonstrated relations with illusory memory creation, did not demonstrate relations with habitual reporting of illusory memories.

The second aim of the present study was to identify individual differences between those individuals identified as habitually susceptible to misinformation and those individuals identified as nonhabitual. The major finding here was an overall failure to find relationships between psychometric measures and habitual susceptibility status. The major exception was the observed association between dissociation and habitual susceptibility. Dissociation broadly refers to the failure to integrate experiences into consciousness and memory. The present association between habitual susceptibility and dissociation supports the findings reported in Hyman and Billings (1998) and Winograd et al. (1998). Moreover, the present relation extends the association of this variable with false memory creation, using a different false memory paradigm. The association reported in Hyman and Billings was obtained with a paradigm designed to create personally relevant false childhood memories, and Winograd et al. obtained their results with a word intrusion paradigm. However, it should be noted that Drivdahl and Zaragoza (2001) failed to find a relation between dissociation and susceptibility to suggestion. Although there are many methodological differences between the present study and the study reported by Drivdahl and Zaragoza, one likely explanation for the discrepant find- 
ings concerns the definition of susceptibility to suggestion. As was alluded to earlier, the present research was focused on individuals with a propensity to habitually report information that was only suggested. In contrast, and as with most misinformation studies, Drivdahl and Zaragoza measured suggestibility on the basis of a single witnessed event. As such, their failure to find a relation between dissociation and suggestibility may be a result of their participants being equated to the individuals identified as nonhabitual in the present study: those accepting suggested information only occasionally, and not habitually (although certainly some of their participants might be considered habitually susceptible, as defined herein, had they been measured on this variable). In addition to the psychometric measures, we included a measure of the association between memory accuracy and confidence. The data replicated those in Tomes and Katz (2000) in demonstrating, overall, a reliable and substantial concordance for items not subject to misinformation but a very low relationship for those subject to postevent misinformation (see Table 3). We extended this finding to demonstrate that habitually susceptible participants exhibit an even greater disconnect between their confidence and accuracy for items subject to misinformation than do nonhabitual participants. This finding, on its face, is consistent with the greater dissociation observed with the habitually susceptible participants.

The failure to replicate the association between imagery and overall memory performance and habitual susceptibility reported in Tomes and Katz (1997) should be noted. The imagery measure used in the present study was a revised version of the one that Tomes and Katz (1997) employed, a difference that may account for this replication failure. It is less clear why the memory performance results did not replicate, although it is possible that the explicit source-monitoring task used in the present study may have influenced performance accuracy on these items. Nonetheless, the same pattern of associations was evident between the present results and those in Tomes and Katz (1997).

The lack of significant relations between the other psychometric variables and habitual susceptibility is less clear. One possibility could be that the manner in which misinformation was presented and assessed in the present study was not sensitive to any potential relations that might exist. Many of the variables used in the present study assessed personality characteristics, and a strong interpersonal context might be required to detect relations between these variables and suggestibility. For example, the relation between locus of control and suggestibility reported by Paddock and colleagues (Paddock et al., 1998; Paddock et al., 2000) was found with a guided visualization technique that increased an individual's susceptibility to suggestion. In both of these studies, susceptibility to suggestion was positively related to an external locus of control, and this finding was explained as resulting from an external reliance on outside sources of information, rather than on personal experience, when personal judgments were made. The failure to find the relation in the present study may be a result of the subtlety of the outside source of information (the misinformation questions), in comparison with the relatively strong source used in the Paddock studies (a male clinical psychologist). Moreover, Porter, Birt, Yuille, and Lehman (2000) have demonstrated an interaction between interviewer/interviewee personality characteristics, so that an extroverted interviewer was able to implant suggestions and receive more false memory reports from an introverted interviewee. As such, it seems plausible to suggest that the personality variables used in the present study might be found to be significantly related to habitual susceptibility if future research were to use a stronger and more interpersonal methodology to implant suggestive information.

Finally, a major aim was to see whether habitual susceptibility status could be related to source attribution. Consequently, we examined explicit source attributions in terms of yes/no responses, to determine whether the pattern of attributions would differ between individuals not exposed to misinformation and individuals exposed to misinformation-specifically, those identified as habitually and nonhabitually susceptible. The pattern of source attributions for the nonmisinformation items is consistent with what would be expected. The results indicated that control, habitual, and nonhabitual participants made similar source attributions when responding correctly and incorrectly to the nonmisinformation items. The participants correctly attributed their correct responses for nonmisinformation items to something they saw in the video event. They also attributed their incorrect responses for these items to something they remembered seeing. Although their initial yes/no response was incorrect in this case, they correctly identified the source from which the memory should have originated. This conclusion is further supported by the relatively few attributions to the other possible source options by each of the three groups, with the tendency for individuals in each group to make a neither or don't know attribution when responding incorrectly to these nonmisinformation items.

As predicted by the source-monitoring framework, nonhabitual individuals, when accepting misinformation, appeared to do so because they failed to correctly identify the source of the misinformation. This conclusion is based on the proportion of saw responses (50\%) when misinformation was accepted, in comparison with their proportion of read responses $(27 \%)$. To speculate, it may be that source misattributions by nonhabitual individuals are a result of a heuristic process that is fast and nondeliberate (Johnson et al., 1993), leading to a plausible inference as to the source of the memory, although this plausible source is incorrect. That is, because the misinformation had been previously encountered in the postevent questions, when the misinformation was encountered on the assessment test, the familiarity of the misinformation biased the response in favor of something that had actually been witnessed in the original event. 
This explanation converges with the results in Bayen, Nakamura, Dupuis, and Yang (2000), in which it was found that failure to remember the source of information led to an attribution based on an expectation of the correct source. Because the participants were instructed that they would be tested on their memory for the event witnessed, in all likelihood, the event witnessed was considered an expected source. If only the misinformation memory trace was available, it should not be surprising that the nonhabituals attributed that memory to this expected source. This expectation-based attribution would also account for the finding that the control group participants also attributed the majority of their incorrect misinformation acceptances (66\%) to something that they thought they had seen in the event witnessed, because for these individuals there was no other plausible source, since they had never been presented with misinformation.

When accepting misinformation, individuals identified as habitually susceptible demonstrated a different pattern of source attributions than the nonhabitually susceptible and the controls did. For this group, they were as likely to attribute their memory to something seen $(39 \%)$ as to something read (38\%). We are left with something of a puzzle: Habitually susceptible individuals are more likely to make correct attributions of source (which is that it was not presented in the event viewed but was presented in written text after the fact) while, at the same time, being more likely to accept the event as having actually occurred. Two possible explanations for this paradox suggest themselves, both of which suggest that habituals are more likely to have access to separate memories for both the original event and the misinformation, consistent with McCloskey and Zaragoza's (1985) contention that, at least for this group of people, postevent misinformation does not overwrite the original event memory.

The first possibility is that habituals are more likely to view both a video event and misinformation items as being an accurate depictions of what they witnessedthus failing to consider that one source may not be a veridical representation of the event witnessed (specifically, the misinformation items). These individuals seem to have some awareness that the information did originate from different sources, as reflected in their pattern of attributions, yet they still maintain a commitment to accepting the misinformation by failing to change their original yes response (see note 3 ). Thus, even though they may accurately remember the source of the information to be the postevent items, they may believe that the postevent questions were, in fact, accurately describing the event. This acceptance could be due to a general tendency for habituals to be more naively accepting of the veracity of accounts or to a lack of confidence in their own memory of the events viewed. The confidenceaccuracy data described earlier would be consistent with a confidence-based account.

A second possibility cannot be discounted: Because habitually susceptible individuals accept more items of misinformation across multiple witnessed events (by definition), they are also able to correctly monitor the source of their memory, at least to some degree. In other words, they are able to make the correct source attribution for misinformation items by responding read, at least some of the time, thus demonstrating less source confusion than the nonhabituals do. We cannot offer an outright rejection of this interpretation on the basis of the data presented. However, it is not clear why they would indicate a yes response (as in yes, I saw it) and then also indicate that they read the misinformation when choosing a source with which to justify the yes response. Perhaps by having their original yes response (which is equivalent to saying saw) available to them when making their explicit attribution, they then indicated read because, in combination, the two are equivalent to responding both, the latter of which is common in this paradigm (see, e.g., Mitchell, Johnson, \& Mather, 2003). ${ }^{9}$

In summary, whatever explanation is found ultimately to be correct, two major points are clear from the source attribution data. First, regardless of group membership, all the participants made similar source attributions when correctly and incorrectly responding to nonmisinformation items and when correctly rejecting misinformation items. The predominate source chosen for these responses was saw, the expected source of event information, and this is consistent with the source-monitoring framework. Second, when falsely accepting items of misinformation, habitually and nonhabitually susceptible individuals exhibited different source attributions patterns. Habituals, much more than nonhabituals, were more likely to make the correct source attribution (i.e., read) but still, paradoxically, to accept the misinformation as having occurred in the event.

In conclusion, the data presented here provide an initial profile of a person who habitually accepts postevent information as part of his or her memory. This person has higher dissociative tendencies, cannot calibrate his or her confidence in the accuracy of his or her memories, and tends to accept misinformation about an event even when recognizing that the information was not present in the experienced event.

\section{REFERENCES}

Bayen, U. J., Nakamura, G. V., Dupuis, S. E., \& Yang, C.-L. (2000). The use of schematic knowledge about sources in source monitoring. Memory \& Cognition, 28, 480-500.

Beck, A. T., Rush, A. J., Shaw, B. F., \& Emery, G. (1979). Cognitive therapy of depression. New York: Guilford.

Bernstein, E. M., \& Putnam, F. W. (1986). Development, reliability, and validity of a dissociation scale. Journal of Nervous \& Mental Disease, 174, 727-735.

Cann, D. R., \& Harris, J. A. (2003). Assessment of the Curious Experiences Survey as a measure of dissociation. Personality \& Individual Differences, 35, 489-499.

Destun, L. M. (1994). Phenomenological characteristics of real and imagined memories: The impact of event valence and individual differences in absorption. Unpublished master's thesis, University of Western Ontario, London, Canada.

Destun, L. M., \& KuiPER, N. A. (1996). Autobiographical memory and recovered memory therapy: Integrating cognitive, clinical, and individual difference perspectives. Clinical Psychology Review, 16, 421 450.

Dobson, M., \& MARKHAM, R. (1993). Imagery ability and source mon- 
itoring: Implications for eyewitness memory. British Journal of Psychology, 32, 111-118.

Drivdahl, S. B., \& Zaragoza, M. S. (2001). The role of perceptual elaboration and individual differences in the creation of false memories for suggested events. Applied Cognitive Psychology, 15, 265281

FARMER, R., \& SUnDBERG, N. D. (1986). Boredom proneness: The development and correlates of a new scale. Journal of Personality Assessment, 50, 4-17.

Goldberg, L. R. (1999). The Curious Experiences Survey, a revised version of the dissociative experiences scale: Factor structure, reliability, and relations to demographic and personality variables. Psychological Assessment, 11, 134-145.

Greene, E., FlynN, M. S., \& Loftus, E. F. (1982). Inducing resistance to misleading information. Journal of Verbal Learning \& Verbal Behavior, 21, 207-219.

GudJONSSON, G. H. (1988). Interrogative suggestibility: Its relationship with assertiveness, social-evaluative anxiety, state anxiety and method of coping. British Journal of Clinical Psychology, 27, 159-166.

Heatherton, T. F., \& Polivy, J. (1991). Development and validation of a scale for measuring state self-esteem. Journal of Personality \& Social Psychology, 60, 895-910.

Higham, P. A. (1998). Believing details known to have been suggested. British Journal of Psychology, 89, 265-283.

Hyman, I. E., JR., \& Billings, F. J. (1998). Individual differences and the creation of false childhood memories. Memory, 6, 1-20.

Johnson, M. K., Hashtroudi, S., \& Lindsay, D. S. (1993). Source monitoring. Psychological Bulletin, 114, 3-28.

Johnson, M. K., \& RAYE, C. L. (1981). Reality monitoring. Psychological Review, 88, 67-85.

Kendall, P. C., Hollon, S. D., Beck, A. T., Hammen, C. L., \& InGRAM, R. E. (1987). Issues and recommendations regarding use of the Beck depression inventory. Cognitive Therapy \& Research, 11, 289-299.

Leary, M. R., Rogers, P. A., Canfield, R. W., \& Coe, C. (1986). Boredom in interpersonal encounters: Antecedents and social implications. Journal of Personality \& Social Psychology, 51, 968-975.

LindsaY, D. S., \& Johnson, M. K. (1989). The eyewitness suggestibility effect and memory for source. Memory \& Cognition, 17, 349-358.

LoFTus, E. F. (1975). Leading questions and the eyewitness report. Cognitive Psychology, 7, 560-572.

LOFTUS, E. F. (1979). Reactions to blatantly contradictory information. Memory \& Cognition, 7, 368-374.

Loftus, E. F., Levidow, B., \& Duensing, S. (1992). Who remembers best? Individual differences in memory for events that occurred in a science museum. Applied Cognitive Psychology, 6, 93-107.

Loftus, E. F., Miller, D. G., \& Burns, H. J. (1978). Semantic integration of verbal information into a visual memory. Journal of Experimental Psychology: Learning, Memory, \& Cognition, 4, 19-31.

Loftus, E. F., \& PALMER, J. C. (1974). Reconstruction of automobile destruction: An example of the interaction between language and memory. Journal of Verbal Learning \& Verbal Behavior, 13, 585589.

MARKS, D. F. (1995). New directions for mental imagery research. Journal of Mental Imagery, 19, 153-167.

MacFarland, W. L., \& Morris, S. J. (1998). Are dysphoric individuals more suggestible or less suggestible than nondysphoric individuals? Journal of Counseling Psychology, 45, 225-229.

McCloskey, M., \& ZaragOZA, M. (1985). Misleading postevent information and memory for events: Arguments and evidence against memory impairment hypotheses. Journal of Experimental Psychology: General, 114, 1-16.

Mitchell, K. J., \& Johnson, M. K. (2000). Source monitoring: Attributing mental experiences. In E. Tulving \& F. I. M. Craik (Eds.), The Oxford handbook of memory (pp. 179-195). New York: Oxford University Press.

Mitchell, K. J., Johnson, M. K., \& Mather, M. (2003). Source monitoring and suggestibility to misinformation: Adult age-related differences. Applied Cognitive Psychology, 17, 107-119.

Nelson, T. O. (1984). A comparison of current measures of the accuracy of feeling-of-knowing predictions. Psychological Bulletin, 95, 109-133.
Nelson, T. O. (1987). The Goodman-Kruskal gamma coefficient as an alternative to signal-detection theory's measures of absolute-judgment accuracy. In E. E. Roskam \& R. Suck (Eds.), Progress in mathematical psychology (Vol. 1, pp. 299-306). Amsterdam: Elsevier.

NowICKI, S., JR., \& DUKE, M. P. (1983). The Nowicki-Strickland lifespan locus of control scales: Construct validation. In H. M. Lefcourt (Ed.), Research with the locus of control construct: Vol. 2. Developments and social problems (pp. 9-51). New York: Academic Press.

Paddock, J. R., Joseph, A. L., Chan, F. M., Terranova, S., ManNING, C., \& LofTUS, E. F. (1998). When guided visualization procedures may backfire: Imagination inflation and predicting individual differences in suggestibility. Applied Cognitive Psychology, 12, S63S75.

Paddock, J. R., Terranova, S., KwoK, R., \& Halpern, D. V. (2000). When knowing becomes remembering: Individual differences in susceptibility to suggestion. Journal of Genetic Psychology, 161, 453468.

Platt, R. D., Lacey, S. C., Iobst, A. D., \& Finkelman, D. (1998). Absorption, dissociation, and fantasy-proneness as predictors of memory distortion in autobiographical and laboratory-generated memories. Applied Cognitive Psychology, 12, S77-S89.

Porter, S., Birt, A. R., Yuille, J. C., \& Lehman, D. R. (2000). Negotiating false memories: Interviewer and rememberer characteristics relate to memory distortion. Psychological Science, 11, 507-510.

Tellegen, A., \& AtKinson, G. (1974). Openness to absorbing and selfaltering experiences ("absorption"), a trait related to hypnotic susceptibility. Journal of Abnormal Psychology, 83, 268-277.

Tomes, J. L., \& KATZ, A. N. (1997). Habitual susceptibility to misinformation and individual differences in eyewitness memory. Applied Cognitive Psychology, 11, 233-251.

Tomes, J. L., \& KATZ, A. N. (2000). Confidence-accuracy relations for real and suggested events. Memory, 8, 273-283.

Tousignant, J. P., Hall, D., \& LofTus, E. F. (1986). Discrepancy detection and vulnerability to misleading postevent information. Memory \& Cognition, 14, 329-338.

WATSON, D., \& FRIEND, R. (1969). Measurement of social-evaluative anxiety. Journal of Consulting \& Clinical Psychology, 33, 448-457.

Winograd, E., Peluso, J. P., \& Glover, T. A. (1998). Individual differences in susceptibility to memory illusions. Applied Cognitive Psychology, 12, 5-27.

\section{NOTES}

1. The sole purpose of employing a control group was to enable an examination of responses between those not exposed to misinformation and those exposed to misinformation. Thus, the utility of the control group lay in performing a manipulation check.

2. It was predetermined before each testing session whether the participants would be completing the source-monitoring task. As such, the participants assigned to both of the experimental conditions and to the control condition were treated identically in this respect. In some cases, all the participants in a particular testing session completed sourcemonitoring tasks, and in other testing sessions, the participants were not required to complete this task.

3. The participants rarely changed their original responses, despite having the opportunity to do so, as is indicated by the mean number of changes occurring for each item type. Specifically, an examination of the 12 misinformation items showed no significant difference in response changes $\left[F(2,92)=0.21, M S_{\mathrm{e}}=0.50\right.$, n.s. $]$ between the control group $(M=0.38)$, the habituals $(M=0.25)$, and the nonhabituals $(M=$ 0.28 ). A similar nonsignificant finding resulted when the number of changes for the 33 items of nonmisinformation was examined $[F(2,92)=$ $0.05, M S_{\mathrm{e}}=2.36$, n.s.], with the respective mean number of changes being the following: control, $M=1.71$; habitual, $M=1.85$; and nonhabituals, $M=1.74$.

4. Although counterbalanced, the multiple video events and questionnaires used in the study leave open the possibility of carryover effects with respect to the misinformation items. Participants may become wise to the fact that there are misinformation items associated with each video event, and as a result, they may be alerted to be aware of this possibility in each successive event, similar to the spill-over effect discussed by Loftus (1979). The responses to misinformation items were 
examined using a $3 \times 3$ split-plot ANOVA to analyze event order and participant condition, with the three video events as the within-subjects factor and the three participant conditions as the between-subjects factor. Only the main effect of event order and the event order $\times$ participant condition interaction are of importance in respect to assessing carryover effects, and no significant differences were found for either of these effects, using the Greenhouse-Geisser adjustment $[F(2,379)=$ $2.19, M S_{\mathrm{e}}=0.80$, n.s., and $F(4,379)=2.10, M S_{\mathrm{e}}=0.80$, n.s., respectively]. These findings rule out the possibility that carryover effects influenced the participants' performance.

5. This method of identifying effective misinformation items was proposed by Loftus et al. (1992), because it identifies only those items that show greater misinformation acceptance by the experimental group, in comparison with the control group.

6. Before the two experimental conditions were collapsed, analyses were conducted to determine whether the participants in the conditions differed in their responses to any of the individual difference measures. There were no significant response differences found between the two conditions on any of the measures. This finding, combined with the fact that a common set of misinformation items was used to identify habit- ually and nonhabitually susceptible individuals, seems to us to be a justification for increasing the power of the present analyses.

7. The criterion variable (habitual susceptibility) for this analysis is dichotomous; as such, a logistic regression analysis is warranted, rather than a linear regression analysis. For interest sake, we also conducted a linear regression analysis, using the criterion variable as a continuous measure, in which individuals could range from 0 to 4 on the measure of habitual susceptibility. A similar pattern of findings was obtained $\left[F(11,148)=5.07, p<.001 ; R^{2}=.29\right.$, adjusted $\left.R^{2}=.23\right]$. Both the misinformation gamma $(\beta=-4.75 ; t=-6.33, p<.001$; partial $r=$ $-.48)$ and the measure of dissociation $(\beta=0.01 ; t=2.33, p<.05$; partial $r=.20$ ) were significant predictors of habitual susceptibility.

8. For this analysis, we have made no distinction between misinformation items that demonstrated a misinformation effect and those that did not, in order to increase the power of the analysis. Our primary interest was in the source attributions made when the participants responded yes or no, regardless of whether a specific misinformation item was more likely to be responded to in a particular manner by the participants in the control or the experimental condition.

9. We thank Marcia K. Johnson for this suggestion. 
APPENDIX A

Misinformation Items

\begin{tabular}{|c|c|c|}
\hline Video & Misinformation Question & Altered Information \\
\hline \multirow[t]{4}{*}{ Big Sweat } & $\begin{array}{l}\text { (P) Think about the male bank employee from whom the two black } \\
\text { suitcases were taken. Was his hair gray? } \\
\text { (BA1) Did the robbers take two black suitcases? }\end{array}$ & $\begin{array}{l}\text { There was one black } \\
\text { suitcase and one beige } \\
\text { duffel bag. }\end{array}$ \\
\hline & $\begin{array}{l}\text { (P) The male bank robber who was wearing a blue-green patterned } \\
\text { shirt and sunglasses, did he take a female teller hostage? } \\
\text { (BA2) Think about the robber who was wearing a blue-green } \\
\text { patterned shirt and who took the female teller hostage. Was he } \\
\text { wearing sunglasses? }\end{array}$ & $\begin{array}{l}\text { The robber was not } \\
\text { wearing sunglasses. }\end{array}$ \\
\hline & $\begin{array}{l}\text { (P) Was a female bank teller, who was standing beside the male } \\
\text { teller, asked to climb over the counter? } \\
\text { (BA3) Was a male teller beside the female teller who was asked to } \\
\text { climb over the counter? }\end{array}$ & $\begin{array}{l}\text { There was no male } \\
\text { teller. }\end{array}$ \\
\hline & $\begin{array}{l}\text { (P) Did the bank robber who was wearing the black leather jacket } \\
\text { and had long dark hair strike any of the bank customers? } \\
\text { (BA4) Did one of the robbers have long dark hair? }\end{array}$ & $\begin{array}{l}\text { The robber had short } \\
\text { hair. }\end{array}$ \\
\hline \multirow[t]{3}{*}{$Z$} & $\begin{array}{l}\text { (P) Did you see the three thugs in the black shirts who threatened } \\
\text { the victim just before the white vehicle tried to run him over? } \\
\text { (ZA1) Was the vehicle that charged the victim white? } \\
\text { (ZA2) When the victim walked through the crowd, prior to his } \\
\text { being attacked, did a group of three individuals approach him? }\end{array}$ & $\begin{array}{l}\text { Only two thugs and the } \\
\text { vehicle was blue. }\end{array}$ \\
\hline & $\begin{array}{l}\text { (P) These thugs, who were wearing black and one of whom was } \\
\text { carrying a stick, did they approach the victim before he was injured? } \\
\text { (ZA3) Think about the thugs wearing black who approached the } \\
\text { victim. Were any of them carrying a weapon? }\end{array}$ & There was no weapon. \\
\hline & $\begin{array}{l}\text { (P) Recall the people who walked down the stairs with the victim } \\
\text { before the attack took place, particularly the man who carried a } \\
\text { clipboard and shouted a warning to the victim. Was this man wear- } \\
\text { ing a dark suit? } \\
\text { (ZA4) When the victim left the building and walked down the } \\
\text { stairs, were any of his companions carrying a clipboard? }\end{array}$ & There was no clipboard. \\
\hline \multirow[t]{4}{*}{$\begin{array}{l}\text { Talons of } \\
\text { the Eagle }\end{array}$} & $\begin{array}{l}\text { (P) The black man being picked up at the airport, who had just arrived } \\
\text { on the American Airlines plane, was he wearing a black jacket? } \\
\text { (TA1) Did one of the witnesses arrive on an American } \\
\text { Airlines plane? }\end{array}$ & $\begin{array}{l}\text { The plane was an } \\
\text { Alaskan Airlines plane. }\end{array}$ \\
\hline & $\begin{array}{l}\text { (P) When the assailant jumped out of the blue pickup truck did he } \\
\text { grab the woman's luggage before he stole her coat? } \\
\text { (TA2) Was the pickup truck that the thief jumped out of blue? }\end{array}$ & $\begin{array}{l}\text { The truck was rust } \\
\text { coloured. }\end{array}$ \\
\hline & $\begin{array}{l}\text { (P) Did the female victim drop her purse onto the ground? } \\
\text { (TA3) Was the female victim carrying a purse? }\end{array}$ & There was no purse. \\
\hline & $\begin{array}{l}\text { (P) While the two witnesses were still in the airport terminal, when } \\
\text { the mother and child walked by them, did the black man introduce } \\
\text { himself to the man who was picking him up? } \\
\text { (TA4) When the two witnesses were introducing themselves in the } \\
\text { airport terminal, did a woman and child walk by? }\end{array}$ & $\begin{array}{l}\text { A mother and child } \\
\text { were not present. }\end{array}$ \\
\hline
\end{tabular}

Note- "P" is indicative of the item that presented misinformation, and "A" indicates the assessment item (e.g., BA1, BA2). 
APPENDIX B

Intercorrelations Among the Individual Difference Variables

\begin{tabular}{|c|c|c|c|c|c|c|c|c|c|c|c|}
\hline & $\begin{array}{c}\text { MI } \\
\text { Gamma }\end{array}$ & $\begin{array}{c}\text { NMI } \\
\text { Gamma }\end{array}$ & Acc & CES & ABS & VVIQ & Dysph & SSES & EXT & FNE & BPS \\
\hline MI gamma & 1.00 & & & & & & & & & & \\
\hline NMI gamma & -.05 & 1.00 & & & & & & & & & \\
\hline Acc & .09 & .10 & 1.00 & & & & & & & & \\
\hline CES & -.06 & -.08 & -.13 & 1.00 & & & & & & & \\
\hline ABS & -.04 & -.01 & -.13 & $.47^{* *}$ & 1.00 & & & & & & \\
\hline VVIQ & -.04 & .04 & -.02 & $.22^{* *}$ & $.42^{* *}$ & 1.00 & & & & & \\
\hline Dysph & -.02 & .14 & -.05 & $.38^{* *}$ & .11 & -.05 & 1.00 & & & & \\
\hline SSES & .09 & .07 & .05 & $-.17^{*}$ & .05 & -.002 & $-.48^{* *}$ & 1.00 & & & \\
\hline EXT & -.10 & -.01 & -.08 & $.30^{* *}$ & $.23^{* *}$ & -.06 & $.42^{* *}$ & $-.45^{* *}$ & 1.00 & & \\
\hline FNE & -.09 & .02 & -.05 & .06 & -.07 & .02 & $.27^{* *}$ & $-.57^{* *}$ & $.32^{* *}$ & 1.00 & \\
\hline BPS & .02 & .12 & .08 & $.27^{* *}$ & -.07 & -.15 & $.43^{* *}$ & $-.35^{* *}$ & $.37^{* *}$ & $.22^{* *}$ & 1.00 \\
\hline
\end{tabular}

Note-MI gamma, misinformation confidence-accuracy gamma; NMI gamma, nonmisinformation items confidence-accuracy gamma; Acc, veridical memory accuracy; CES, dissociation; ABS, absorption; VVIQ, imagery use; Dysph, dysphoria; SSES, state self-esteem; EXT, external locus of control; FNE, fear of negative evaluation; BPS, boredom proneness. ${ }^{*} p<$ $.05 .^{* *} p<.01$.

(Manuscript received March 8, 2002;

revision accepted for publication July 18,2004 .) 